\title{
Prevenção da AIDS em idosos: visão e prática do enfermeiro
}

\author{
AIDS prevention in old-age people: nurse's view and practice
}

\author{
Susane de Fátima Ferreira de Castro ${ }^{1}$, Aline Aragão da Costa $^{2}$, Luciane Alves de \\ Carvalho $^{3}$, Francisco de Oliveira Barros Júnior ${ }^{4}$
}

\begin{abstract}
RESUMO
Objetivo: Descrever e analisar a visão e prática de enfermeiro da estratégia saúde da família acerca da prevenção da AIDS em idosos.

Materiais e Métodos: Trata-se de uma pesquisa exploratória, de abordagem qualitativa, realizada nas Unidades Básicas de Saúde. Os participantes do estudo foram dez enfermeiros que prestam assistência aos idosos nas Unidades Básicas de Saúde a mais de três anos, de ambos os sexos, que aceitaram participar, mediante a assinatura do termo de consentimento livre esclarecido. Os dados foram coletados por meio de um roteiro de entrevista semiestruturado e analisados a partir do agrupamento das falas em categorias temáticas, seguindo a trajetória analítico-interpretativa de Minayo.

Resultados: Os discursos produzidos permitiram a construção de três categorias: uma questão emergente; ações pontuais e fragmentadas; uma lacuna na atenção à saúde do idoso. A visão e prática da prevenção da AIDS pelo enfermeiro na Estratégia Saúde da Família ainda é muito restrita ao uso do preservativo e atrelado a outros programas em que o idoso está inserido, como o programa hiperdia e as consultas que envolvem o exame de citologia para prevenção do câncer de útero.

Conclusão: Observou-se que há um preconceito, ancorado em questões de cunho cultural, por parte do enfermeiro sobre a sexualidade do idoso, e isso consequentemente reflete na falta de ações e estratégias eficazes de prevenção da AIDS nessa faixa etária.
\end{abstract}

Palavras-chave: idoso; enfermagem; síndrome da imunodeficiência adquirida; estratégia saúde da família.

\begin{abstract}
Objective: To describe and analyze the nurse's point of view and practice in the family health strategy about the AIDS prevention in elderly.

Materials and Methods: It is an exploratory survey, with qualitative approach, conducted at the Primary Health Care Units. The participants were ten nurses who assist older patients in the Primary Health Care Units for more than three years, of both genders and agreed to participate by signing the informed consent form. The data were collected through a semi-structured interview and analyzed from the grouping of the statements in thematic categories, following the Minayo's analytical interpretative perspective.

Results: Three thematic categories were identified: an emerging issue, punctual and fragmented actions, lack in attention to old age people health. Nurse's view and practice of AIDS prevention in the Family Health Strategy is still very restricted to the use of preservative and linked to other programs where the elderly is inserted, such the "Hiperdia" Program and gynecologycal appointments.

Conclusions: It was observed that there is a prejudice, based on cultural issues, by nurses about the sexuality of the senior people which, thereafter, reflects the lack of effective actions and strategies for AIDS prevention in this age group.
\end{abstract}

Keywords: elderly; nursing; acquired immunodeficiency syndrome; family health strategy.

\footnotetext{
${ }^{1}$ Enfermeira. Doutoranda em Políticas Públicas pela Universidade Federal do Piaú (UFPI). Faculdade de Tecnologia e Educação Superior Profissional (FATESP) e Hospital Getúlio Vargas.

${ }^{2}$ Enfermeira graduada pelo Centro Universitário de Ciências da Saúde, Humanas e Tecnológicas do Piauí - UNINOVAFAPI.

${ }^{3}$ Enfermeira graduada pelo Centro Universitário de Ciências da Saúde, Humanas e Tecnológicas do Piauí - UNINOVAFAPI.

${ }^{4}$ Cientista Social. Doutor em Sociologia. Professor da UFPI.
} 


\section{INTRODUÇÃO}

Atualmente no Brasil é evidente o envelhecimento da população, em que existem mais de 14,5 milhões de idosos, com uma perspectiva de aumento para 32 milhões em 2025, devido à diminuição nos índices de natalidade e fecundidade nos últimos anos, e do aumento da longevidade favorecido pelos avanços tecnológicos na área da saúde ${ }^{1}$.

No lastro dessa discussão, políticas de saúde voltadas para os idosos foram elaboradas com o propósito de contribuir para que um maior número de pessoas alcance, não somente um maior número de anos vividos, mas um envelhecimento bem sucedido. Dentre essas políticas, ressalta-se o Estatuto do Idoso e a Política Nacional de Atenção à Saúde da Pessoa Idosa (PNASPI) ${ }^{2}$.

O Estatuto do Idoso é a forma legal criada para regulamentar os direitos fundamentais da pessoa idosa e amparar o direito de atenção integral à saúde do idoso. A PNASPI, por sua vez, aborda que cabe ao setor saúde promover o acesso dos idosos aos serviços de saúde, prestar assistência integral e realizar ações voltadas à promoção, proteção e recuperação da saúde, visando manutenção e melhoria da capacidade funcional dos idosos, em uma visão interdisciplinar, mediante o estabelecimento de normas específicas para tal $^{3}$.

A prática desenvolvida na realidade dos serviços de saúde, no entanto, está na contracorrente desses dispositivos legais, sendo perpassada por um cuidado fragmentado ao indivíduo idoso, ancorada na visão biologicista do envelhecimento, deixando-se na invisibilidade dimensões importantes em qualquer fase da vida, como a vivência da sexualidade. Em virtude disto, o número de casos de pessoas idosas com doenças sexualmente transmissíveis (DST) tem aumentado de forma significativa, dentre elas a AIDS (Síndrome da Imunodeficiência Adquirida), trazendo para o envelhecer novas questões físicas, emocionais, psicológicas e sociais ${ }^{4}$.

A AIDS é, ainda, considerada um problema relevante na atualidade, pelo seu caráter epidêmico, cuja forma de ocorrência acontece nas diferentes regiões do mundo, e todas as faixas etárias estão vulneráveis. No Brasil, nas ultimas três décadas foram notificados 371.827 casos, sendo que $6,2 \%$ desse valor são de pessoas entre 50 a 59 anos e 2,1\% de indivíduos com mais de 60 anos, entre ambos os sexos ${ }^{3}$.

$\mathrm{Na}$ velhice, a AIDS assume nuances particulares, significando, no mínimo, uma dupla contaminação, uma vez que 0 entrecruzar dessas duas fontes de discriminação produz nos idosos marcas que mancham, que minam suas identidades, suas experiências, além do que remodelam o ser e estar no mundo dessas pessoas. O preconceito atrelado à AIDS se mantém vivo, cobrando das pessoas idosas portadoras do vírus HIV um alto preço em termos de sofrimento, isolamento e solidão, sobretudo porque a discriminação advém principalmente de familiares e pessoas próximas, restringindo a de rede apoio dessas pessoas, algo reconhecidamente significativo para um enfrentamento positivo da doença ${ }^{4}$.

Diante dessa realidade de sofrimento, é premente trabalhar a prevenção da AIDS nessa fase da vida e, nesse contexto, a Estratégia Saúde da Família (ESF) aparece como um local privilegiado para essas ações, por ser a porta de entrada da assistência dos serviços de saúde, por construir um processo de trabalho pautado na equipe multiprofissional e, também, por sua lógica territorial, que possibilita maior proximidade com a população, permitindo um reconhecimento mais fidedigno do perfil e demandas dos indivíduos idosos, algo de extrema relevância para a elaboração de estratégias que possam de fato alcançar a realidade dessas pessoas, produzindo melhorias nas múltiplas dimensões que permeiam o envelhecer ${ }^{5}$.

Uma das atribuições da atenção básica é desenvolver ações de prevenção às DST e à AIDS, estimulando o uso do preservativo, ação relevante para se evitar o contágio durante a relação sexual, diminuindo assim o número de novos casos, realizando atividades para aumentar a procura pelo teste do HIV, diminuindo o diagnóstico tardio, e consequentemente melhorando a qualidade de vida das pessoas que vivem com o vírus, além de melhorar o acesso ao tratamento, a adesão e a assistência das pessoas que vivem com a $\operatorname{AIDS}^{5}$.

Portanto, faz-se necessário que preconceitos e indiferenças atribuídos à velhice e à AIDS sejam 
desconstruídos para que os idosos sejam vistos na sua integralidade, e não apenas como pessoas doentes e incapazes. É necessário que esse segmento seja favorecido na implementação das políticas públicas sociais, para que possa, enfim, diminuir a vulnerabilidade e o sofrimento imposto pela vivencia de uma doença martirizante.

Face ao exposto, o estudo tem como objetivo descrever a visão e a prática do enfermeiro da ESF ou UBS acerca da prevenção da AIDS em idosos. Nesse sentido, a pesquisa aqui proposta assume papel significativo como instrumento de informações para enriquecer o conhecimento dos profissionais de saúde sobre a temática, torná-los consciente da necessidade de vislumbrar os idosos como pessoas capazes de viver plenamente a sua sexualidade e, assim, vulneráveis à AIDS, e fazê-los refletir sobre a importância de trabalhar a prevenção dessa patologia em idosos.

A percepção que a sociedade tem da pessoa idosa envolve muitos mitos e tabus, o que influencia a prática dos profissionais de saúde junto aos idosos, requerendo, assim, estudos que possibilitem a discussão desse assunto, de modo a fornecer subsídios para a construção de um agir diferente frente à velhice, pautado na integralidade das ações ${ }^{4}$.

\section{MATERIAIS E MÉTODOS}

Trata-se de uma pesquisa exploratória de abordagem qualitativa, realizada nas Unidades Básicas de Saúde (UBS) que possuem equipes de ESF e profissionais enfermeiros que se enquadrem nos critérios de inclusão propostos na pesquisa.

Os participantes da pesquisa foram 10 enfermeiros (as) da ESF, quantidade definida pela saturação dos discursos produzidos no decorrer da coleta dos dados, escolhidos de forma aleatória, independente de sexo, raça, etnia e idade, que prestam assistência aos idosos nas UBS a mais de três anos e que aceitaram participar da entrevista, após assinatura do Termo de Consentimento Livre e Esclarecido (TCLE).

A coleta de dados foi norteada por um roteiro de entrevista semiestruturada aplicado pelas próprias pesquisadoras nos turnos de funcionamento das UBS, em um consultório fechado para garantir a privacidade dos participantes, com duração média de 20 minutos, em horários previamente agendados com os participantes. Foi utilizado um gravador para registro das falas dos entrevistados, seguida da organização e classificação dos relatos, respondendo aos objetivos do estudo e posteriormente foram transcritas para fins de análise e interpretação.

O processo de análise dos dados ocorreu concomitantemente à coleta destes, com o intuito de determinar a quantidade de entrevistas pela saturação das falas produzidas pelos participantes, a partir de leituras verticais e horizontais do material construído, a fim de proporcionar uma apropriação dos discursos dos participantes e permitir a organização destes em categorias temáticas para posterior análise e interpretação à luz do referencial teórico da questão aqui abordada, seguindo a trajetória analíticointerpretativa de Minayo ${ }^{7}$.

Nesse intento, os caminhos para interpretação das falas dos sujeitos participantes da pesquisa seguiram as seguintes etapas: leitura compreensiva do material selecionado, em que se buscou, de um lado, ter uma visão de conjunto e, de outro, apreender as particularidades do material; exploração do material, sendo considerado de fundamental importância ser capaz de ir além das falas e dos fatos ou, em outras palavras, caminharmos na direção do que está explícito para o que é implícito, do revelado para o velado, do texto para o subtexto; e elaboração de síntese interpretativa, fazendo-se uma articulação entre os objetivos do estudo, a base teórica adotada e os dados empíricos ${ }^{7}$

Foram observados os aspectos éticos que regem pesquisas com seres humanos, conforme Resolução 466/12, do Conselho Nacional de Saúde. O projeto foi autorizado pelo Comitê de Ética em pesquisa (CEP) do Centro Universitário de Saúde, Ciências Humanas e Tecnológicas do Piauí - UNINOVAFAPI, com o CAAE no 18364113.2.0000.5210.

\section{RESULTADOS E DISCUSSÃO}

Participaram do estudo 10 enfermeiros, dos quais a maioria é do sexo feminino, apenas um do sexo masculino, com idades que variam de 24 a 56 anos. 
Quanto ao estado civil a maioria é casada, com tempo de atuação na ESF entre 3 a 18 anos, sendo que nenhum dos sujeitos possui especialização em saúde do idoso e todos possuem especialização na ESF.

Os discursos produzidos durante as entrevistas permitiram a construção de três categorias temáticas: AIDS na velhice como uma questão emergente; Ações pontuais e fragmentadas voltadas para a prevenção da AIDS na velhice; Uma lacuna na atenção à saúde do idoso.

\section{AIDS na velhice como uma questão emergente}

Os participantes do estudo demonstram, a partir dos discursos produzidos durante as entrevistas, uma visão da AIDS na velhice como um problema novo e atual, uma questão emergente, o que os enfermeiros atrelam ao fenômeno do envelhecimento da população, de modo que se as pessoas estão vivendo mais, se tornam mais susceptíveis a uma série de condições antes não cogitadas, conforme expressam as falas abaixo.

Uma coisa que agente nega, você quase não via né! Nada assim em relação a isso, como se agente desconhecesse realmente esse agravo na terceira idade, na velhice (E3).

É um tema atual por se tratar que antigamente ao meu ponto de vista não se tinha tanta essa preocupação, e hoje em dia, éh não existe mais grupo de risco né, hoje em dia todos nós somos grupos de risco $[\ldots](\mathrm{E} 4)$.

[...] ééé uma doença que esta realmente atingindo essa faixa etária até porque as pessoas estão vivendo mais, consequentemente estão se expondo HIV [...] (E2).

Em 2025 o Brasil se tornará o sexto país do mundo a conviver com uma população numerosa de idosos. Segundo dados do Instituto Brasileiro de Geografia e Estatística (IBGE), considerando a continuidade das tendências verificadas para as baixas taxas de fecundidade e aumento na expectativa de vida, consequentemente na longevidade da população brasileira, as estimativas para os próximos 20 anos indicam que a população idosa pode exceder 30 milhões de pessoas. Em virtude dessa mudança no perfil da população, que vem acarretando novos olhares e planejamentos por parte dos gestores em saúde, observa-se a formulação e implementação de políticas públicas direcionadas ao idoso e que visam proteger essa faixa da população em todos os seus aspectos, assegurando integralidade em seus direitos ${ }^{8}$.

Dentre essas políticas, destaca-se a PNASPI, que tem a intenção de promover a prevenção, promoção, proteção e recuperação da saúde da população idosa e o Estatuto do Idoso que visa garantir ao idoso os direitos fundamentais de proteção à vida e dentre eles os relacionados à saúde. Porém, apesar desses aspectos positivos no plano teórico, ainda há muito que se fazer na prática junto aos idosos, haja vista uma necessidade de vislumbrar o idoso em todas as suas dimensões, reconhecendo a sexualidade como algo possível de se viver na velhice, dimensão negada pela sociedade e pelos profissionais de saúde, no sentido de não se trazer à baila tal questão para discussão entre as pessoas de idade mais avançada ${ }^{4}$.

Um cenário que abre portas para doenças não consideradas como pertencentes ao rol daquelas que acometem os indivíduos idosos. As atenções estão direcionadas, sobretudo, para a Hipertensão Arterial e o Diabetes Melitus. Em que pese a relevância epidemiológica e social dessas enfermidades, outros agravos permanecem à sombra das imagens negativas sobre a velhice como uma fase de fragilidades e incapacidades ${ }^{4}$.

Nesse contexto, a AIDS e outras DSTs não são reconhecidas como realidades possíveis no envelhecimento. Todavia, no Brasil, houve um crescente número de idosos infectados por essas doenças, de $7 \%$ em 1996 para $13 \%$ em $2004^{9}$. Isso possivelmente se justifica pela ausência de campanhas preventivas voltadas para o idoso, uma vez que a sociedade considera essa parcela da população seres assexuados, além de atribuírem tabus e preconceito à sexualidade nessa faixa etária. Dessa forma, a prevenção às DSTs e AIDS para o idoso torna-se um desafio para os profissionais de saúde e responsáveis pelas políticas públicas ${ }^{9}$.

Além disso, a falta de abordagem dos profissionais da saúde em relação à sexualidade no envelhecimento implica em dificuldades para a orientação dos idosos 
sobre tal assunto ${ }^{7}$. Devido à estigmatização do idoso, os familiares e profissionais de saúde negam-se a pensar que nessa fase o indivíduo está sexualmente ativo.

As formas de prevenção dessas doenças e a sexualidade nos idosos podem ser trabalhadas por meio de educação em saúde, visto que esta constitui um recurso para prevenção de doenças e promoção da saúde, em que o conhecimento científico, por intermédio dos profissionais da saúde, atinge a vida cotidiana das pessoas levando-as a compreender os condicionantes do processo saúde-doença, oferecendo, dessa forma, subsídios para adoção de novos hábitos e condutas de saúde ${ }^{10}$.

Verifica-se estar diante de uma questão cultural e de exclusão, concentrada, principalmente, nos preconceitos sociais relacionados à sexualidade na velhice. Diante disso, ao colocar a AIDS na velhice como uma questão emergente os participantes do estudo associaram tal cenário ao uso das drogas para disfunção erétil, situação acompanhada da ausência do hábito de usar preservativos entre as pessoas idosas.

O idoso hoje em dia, principalmente o homem por conta dos novos medicamentos que potencializam a história do Viagra, do advento desses medicamentos, os homens eles se preocupam em ter a relação, em tomar o remédio, ter a ereção, tem a relação e não se preocupam em usar a camisinha, preservativo e ao meu ver isso contribuiu muito com a história da AIDS na velhice" (E4).

Eu vejo a AIDS na velhice como um problema principalmente com o advento de medicamentos como Viagra, como Cialis... A atividade sexual nos idosos ela aumentou bastante, então eles tem relação sexual sem nenhum preservativo aí o risco de AIDS aumenta [...] (E5).

Após o desenvolvimento de drogas que melhoram o desempenho sexual, o uso de prótese para disfunção erétil para os homens e reposição hormonal para as mulheres, os idosos, tornaram-se cada vez mais ativos sexualmente. Todo este avanço veio na tentativa de promover qualidade de vida e uma vida sexual ativa para o idoso ${ }^{10}$.
O uso de medicações para tratar a disfunção erétil é um elemento importante no contexto dessa discussão sobre a sexualidade na velhice. No entanto, elas respondem por um verdadeiro paradoxo que permeia essa temática, uma vez que se reconhece sua existência, seu uso entre os idosos, porém, não se conversa sobre esse conteúdo nas abordagens nos serviços de saúde, produzindo lacunas na atenção a esses indivíduos e contribuindo para práticas inadequadas que acabam influenciando negativamente na saúde dos idosos.

$\mathrm{Na}$ esteira dessa discussão, o preservativo aparece como outro elemento importante mencionado pelos enfermeiros sujeitos da pesquisa no desenho desse panorama que permeia a AIDS na velhice. Culturalmente, tal insumo é cercado pela ideia de finalidade contraceptiva, para evitar uma gravidez indesejada. Além disso, a prática do uso do preservativo não faz parte da construção das experiências sexuais dos idosos ${ }^{11}$.

Há uma resistência à cultura do uso do preservativo pelo idoso, por diversas razões, como falta de informação, por achar que já está no final da vida e não vai ter problema em adquirir uma doença nessa fase da vida, por dificultar a ereção e o desempenho sexual e, diminuição da sensibilidade com o uso do preservativo, dentre outros motivos ${ }^{12}$.

A possibilidade de um idoso ser infectado pelo vírus HIV parece invisível aos olhos da sociedade, e também dos próprios idosos, que não tem a cultura do uso do preservativo. Também as mulheres, nesta faixa etária, por em geral não poderem engravidar, têm a falsa impressão da inutilidade do preservativo. Há uma falta de identificação do idoso com as campanhas de prevenção da AIDS, que tem sempre como foco o jovem. Então, o idoso não se considera como um doente em potencial ${ }^{13}$.

No entanto, a prevenção das DST para os idosos não acompanhou o ritmo desta evolução. Por estas razões, esses indivíduos se expõem, cada vez mais, a situações de vulnerabilidade, que além de estarem relacionadas às atitudes pessoais, se estendem à dificuldade em diagnosticar precocemente o vírus HIV nesta faixa etária. Isto porque nem sempre sua vida sexual é 
questionada nas consultas, predominando o mito de que têm ritmo sexual diminuído ou já não fazem sexo ${ }^{8}$.

A melhoria do desempenho sexual por meio da utilização de medicamentos, fez com que os idosos ficassem mais confiantes, tendo assim sua vida sexual ativa novamente, porém, a ausência da utilização do preservativo é um fator prejudicial ao desempenho sexual, os expõe aos riscos de contrair uma DST/AIDS, tal comportamento de risco ocorre devido ao baixo nível de conhecimento em educação sexual ou no meio social em que está inserido ${ }^{14}$.

Todas essas razões tornam o idoso um cidadão vulnerável a doenças como a AIDS e cria a necessidade de ações e estratégias educativas para a prevenção da AIDS nos idosos e uma mudança de comportamento por parte destes e da sociedade como um todo, e principalmente dos profissionais da atenção básica que são aqueles que acompanham de perto a saúde do idoso que vive na comunidade ${ }^{4}$.

\section{Ações pontuais e fragmentadas}

Os enfermeiros participantes da pesquisa demonstraram, no decorrer das entrevistas quando indagado sobre o seu trabalho na prevenção da AIDS na velhice no contexto das suas práticas na ESF, realizar ações pontuais de prevenção, sendo que a prevenção da AIDS em idosos acontece apenas de forma individual, como durante a realização do exame de citologia para prevenção do câncer de colo uterino e a grupos específicos, como de usuários diabéticos e hipertensos, deixando à margem dessa prevenção aqueles idosos que não se encaixam nesses nichos de atenção ou não frequentam o posto de saúde, tal como expressa as falas citadas:

Hoje nós temos os grupos da terceira idade que nós trabalhamos principalmente a questão é do hipertenso, do diabético e envolvido a isso nós trabalhamos as outras modalidades de programas e trabalhamos as DSTs (E1).

Na ESF agente tem um dia que faz citologia, então nesse dia da citologia é um dia que agente aborda as idosas né, então as idosas que fazem a citologia agente tenta abordar com relação a sexo seguro, como são as práticas sexuais (E2).

[...] agente trabalha em condição do acompanhamento do hipertenso, diabetes, na citologia, na questão do planejamento familiar e nas orientações que agente faz na demanda espontânea que tem (E7).

[...] agente faz as orientações individuais, eu aproveito as consultas de rotinas de hipertensão e diabetes e as de coletas de citologia para investigar [...] (E9).

A velhice geralmente associada à doença é uma concepção incorreta, visto que grande parte dos idosos continua com independência e autonomia preservados. A ênfase demasiada na doença desconsidera os aspectos sociais, relegando-os a um plano secundário; por isso é necessária uma compreensão mais abrangente e adequada de um conjunto de fatores que compõem a vida do idoso, de entendimento da velhice como uma fase da vida atravessada por múltiplas dimensões, muitas destas invisíveis, como é o caso da sexualidade $^{15}$

A sexualidade na velhice não é levada em consideração nos espaços de atenção à saúde do idoso, tal como ocorre com muitos outros aspectos da vida privada. Isso porque se mantém uma visão hegemônica do envelhecer fundamentada na perspectiva do adoecer, fomentando ações que buscam mais controlar esses sujeitos do que o desenvolvimento da autonomia individual.

Ressalta-se a necessidade, por parte dos profissionais da saúde, da compreensão da sexualidade presente no cotidiano dos idosos e de suas possíveis manifestações. Uma vez que as ações de enfermagem devem estar voltadas para ajudar o idoso a lidar com suas próprias realidades e os demais a compreenderem as realidades do outro, pois são naquele contexto que ocorrem todas essas representações ${ }^{16}$.

Além disso, a biomedicalização do envelhecimento em função das doenças que se manifestam nesta fase com maior frequência pressupõe uma série de controles sociais em relação à velhice a partir do paradigma biomédico, que prioriza a patologia e seus tratamentos. Essa questão tem influenciado significativamente a atenção à saúde do idoso e levado à ausência de ações direcionadas para a vivência da sexualidade nesse 
momento da vida ${ }^{17}$.

Observou-se a partir das falas dos enfermeiros, que ainda não houve um despertar por parte destes profissionais para incorporar às suas ações as questões relativas à prevenção da AIDS. E que se há algum tipo de prevenção, ainda é bem discreta e associada a outros programas e ao uso do preservativo.

Grande parte dos entrevistados referiu uma abordagem sobre o tema nas mulheres idosas somente quando fazem os exames da citologia, quando se abre uma porta para entrar no assunto sem parecerem indiscretas. O enfermeiro deve primeiro conhecer seu próprio julgamento sobre a velhice e a sexualidade e assim poder através desse conhecimento intervir sem preconceito.

A maioria das ações que praticam os sujeitos do estudo no contexto da atenção à saúde do idoso inserese no lidar com as doenças crônicas, sobretudo hipertensão e diabetes, no programa hiperdia. Neste, o atendimento é voltado apenas para ações pontuais, deixando de lado a visão do paciente sobre os outros aspectos do seu envelhecer.

O foco da atenção básica é proporcionar e criar ações em saúde, por meio da promoção e prevenção de doenças na população. E como advento da AIDS, se faz necessária a abordagem dessa temática nas UBS por parte dos profissionais de saúde, e que haja um atendimento preventivo eficaz e eficiente à esses idosos, pois um dos motivos do aumento da AIDS na velhice está relacionado diretamente à falta de acesso a serviços de saúde efetivos ${ }^{16}$.

A ESF, por atuar num território delimitado, estabelece vínculo mais facilmente, acelerando o processo de participação individual e coletiva e troca de experiências positivas que podem resultar em modificações saudáveis de comportamentos. O programa brasileiro de DST/AIDS estabelece que o papel do enfermeiro da ESF é que irá referenciar ao indivíduo portador do vírus HIV para um infectologista após o diagnóstico, isso em um contexto em que múltiplas intervenções preventivas e assistenciais seriam possíveis ${ }^{18}$.

Sendo assim, deveria ser incluso na ESF a prevenção e controle da infecção pelo HIV em pessoas idosas nas suas atividades de consulta, como o faz com relação aos fatores de risco para doenças sistêmicas prevalentes na sociedade atual. Uma rede de atenção à AIDS centrada no nível primário favoreceria o cuidado integral dos pacientes e a educação das famílias e comunidades, e possivelmente, favoreceria a estruturação de sistemas de referência locais e regionais para os níveis especializados de cuidado requeridos eventualmente por estes pacientes ${ }^{6}$.

Com isso, abordar o tema da prevenção da AIDS na velhice, é reconhecer as peculiaridades dessa vivência da sexualidade do idoso, levar em consideração os aspectos relacionados a essa sexualidade e abordá-las através de uma perspectiva multidimensional.

Nas falas anteriormente citadas, os sujeitos deixam claro que a única orientação que eles fazem para a prevenção da AIDS nas UBS é quanto ao uso do preservativo. De fato o uso do preservativo é a melhor forma de evitar a infecção, porém restringir as orientações apenas ao uso dele torna a prevenção da AIDS bastante restrita e fragmentada.

Há a necessidade premente de ações preventivas além do uso do preservativo, como conhecimento da doença, levando em conta as peculiaridades inerentes a essa faixa etária como ressecamento vaginal, desinteresse sexual causada por problemas hormonais, impotência masculina e dificuldade de ereção, uso indiscriminado de medicações que favorecem o desempenho sexual, limitação social e pessoal, desinformação e com isso uma diminuição na vulnerabilidade do idoso à AIDS.

Ainda há pouca ênfase desses profissionais em prevenção, fazendo-se necessário o uso de estratégias de intervenção mais eficazes como educação contínua e específica voltada para a saúde do idoso, conscientização da vulnerabilidade e dos fatores de risco, disseminação da informação para reconhecimento de sinais e sintomas, busca precoce por assistência, convocação de parceiros, campanha em mídia entre outros, para diminuir a disseminação da doença ${ }^{19}$.

\section{Uma lacuna na atenção à saúde do idoso}

Apesar da realidade exposta pelos participantes do estudo, na qual estes vislumbram a AIDS na velhice como um problema emergente, ao tempo em que, por 
outro lado, trabalham no seu cotidiano ainda de forma pontual e fragmentada no tocante à temática aqui abordada, percebe-se que tais profissionais reconhecem que se trata de uma lacuna dentro da sua prática nos serviços de saúde, o que requer mudanças e novos direcionamentos, como expressam as falas a seguir.

[...] eu já havia conversado com os agentes sobre esse assunto, pra gente ou falar (E4)

[...] é um grupo também que está vulnerável, então precisamos ta chegando antes dessas doenças... aparecerem nessa faixa etária (E3)

Um dia que eu vou escolher para trabalhar esse tema, que não tá sendo trabalhado ainda né! Mais que eu vou escolher para trabalhar esse tema por que eu acho de extrema relevância (E4)

Ainda não trabalhei mais tenho plano de começar a fazer palestras educativas sobre a AIDS. (E8).

O conhecimento das necessidades de saúde dos idosos revela-se como possibilidade de aprimoramento do cuidado a essa parcela populacional, de modo a promover a manutenção da capacidade funcional, com preservação da autonomia e da independência. Ademais, é fundamental uma assistência que priorize não apenas as demandas biológicas, como também as alterações que podem comprometer a dimensão psicossocial da pessoa que envelhece ${ }^{20}$.

Cabe aos profissionais de saúde, em especial ao enfermeiro, identificar as necessidades individuais dos idosos e planejar ações/estratégias, com enfoque nas suas demandas, no intuito de promover um envelhecimento ativo e saudável, que possibilite a manutenção da autonomia e da independência, a preservação da sua capacidade funcional ${ }^{19}$.

Ressalta-se que uma assistência voltada para as necessidades de saúde requer atenção aos aspectos objetivos e subjetivos da vida do idoso, respeitando seu modo de ser e pensar. Para tanto, é preciso repensar e redescobrir prioridades para ao planejamento das ações de saúde. Assim, o cuidado na perspectiva apresentada transcende sua dimensão tecnológica, possibilitando uma assistência de enfermagem individualizada e humanizada ao idoso ${ }^{19}$.
Porém, para que se obtenha atenção qualificada e resolutiva aos idosos, é necessária a formação de profissionais, entre estes o enfermeiro, devidamente preparado para visualizar a tenacidade da instalação de processos patológicos nos idosos, que podem, facilmente, mudá-lo de independente para dependente. Enfim, conscientizar-se que 0 idoso apresenta necessidades diferentes dos demais adultos, que são inerentes ao processo de envelhecimento ${ }^{20}$.

Há uma justificativa para não realização de ações voltadas para a AIDS na velhice pautada no não conhecimento de pacientes idosos soropositivos na comunidade, como segue nas falas abaixo:

[...] nós trabalhamos esses grupos é como um todo, nós não temos um grupo específico até por que não temos paciente do nosso conhecimento detectado (E1).

A gente não tem nenhum caso de diagnosticado até o momento em pessoas com mais de 60 anos (E2).

[...] nunca tive um caso ainda na nossa equipe, nunca nos deparamos com nenhum caso (E10).

A ação da enfermagem junto ao idoso no contexto da Atenção Básica implica um diálogo permanente, sendo uma experiência intersubjetiva, que tem como lócus central pessoas, o idoso e o profissional de enfermagem e para isso o caminho a ser escolhido para esta descoberta direciona para um olhar compreensivo voltado para um mundo de vivências e experiências do idoso revelando suas necessidades de saúde sentidas $^{21}$.

Para que os profissionais de saúde vejam os idosos como vulneráveis ao vírus HIV, é necessário o enfoque da integralidade na atenção à saúde e esta deve ser uma das perspectivas utilizadas na ESF para as práticas de saúde. Nesse sentido, atuação na abordagem integral não é somente no aspecto da prevenção, também a responsabilização, o vínculo, o acolhimento e a humanização são elementos essenciais ${ }^{22}$.

$\mathrm{Na}$ busca pela assistência integrada está implícita a necessidade de organizar o trabalho de forma a favorecer uma assistência direcionada a demanda individual de cada idoso e familiar, deste modo exige-se cada vez mais a atuação de profissionais competentes e 
habilitados ${ }^{23}$.

A unidade básica é a porta de entrada do usuário no sistema de saúde e possui menor complexidade no sistema no que se refere a utilização de tecnologias matérias, recursos técnicos e laboratoriais, mas apresenta-se como um local de grande complexidade tecnológica quanto ao processo de trabalho necessário para realizar intervenções individuais e coletivas eficazes, nos problemas de saúde ${ }^{6}$.

Organizar o processo de trabalho para ofertar uma assistência integral, acolher as demandas da população e ao mesmo tempo desenvolver ações de saúde pública não é tarefa fácil, pois depende da articulação e integração de diversos campos do conhecimento, da atuação de cada trabalhador e da interação de diferentes trabalhos. Contudo, é uma necessidade posta na realidade dos serviços de saúde como forma de materializar as políticas públicas destinadas à população idosa, pautadas na visão integral do ser humano que envelhece, conquistas legais significativas, porém, ainda sem expressividade prática no cotidiano das pessoas idosas.

\section{CONSIDERAÇÕES FINAIS}

De acordo com o objetivo proposto constatou-se que a visão e prática da prevenção da AIDS no idoso pelo enfermeiro na ESF ainda é muito restrita ao uso do preservativo e atrelado a outros programas em que esse indivíduo está inserido, como o programa de Hipertensão e Diabetes e as consultas que envolvem o exame de citologia para prevenção do câncer de útero.

Observou-se que há preconceito, ancorado em questões de cunho cultural por parte do enfermeiro sobre a sexualidade do idoso, e isso consequentemente reflete na falta de ações de prevenção da AIDS nessa faixa etária.

O estudo aponta, ainda, que os idosos estão vulneráveis à AIDS na medida em que os participantes do estudo relatam a não abordagem dos idosos a respeito de ações preventivas no tocante à essa doença. Portanto, há necessidade de desenvolver estratégias de prevenção quanto aos meios de transmissão do HIV, no intuito de envolver esses indivíduos no processo de conhecimento acerca da
AIDS e, sobretudo, na mudança de comportamento.

Cumpre mencionar, que no decorrer da pesquisa, algumas limitações permearam a etapa de construção dos dados, em que os participantes demonstraram dificuldade em expressar sua visão ainda acerca da AIDS na velhice, pois conforme os relatos tornam-se evidente ser um tema novo e que ainda não haviam sido indagados acerca de suas ideias e ações em relação a AIDS no idoso.

Espera-se que essa pesquisa possibilite um repensar para implementação de ações de cuidados integrais voltados para os idosos, e chame a atenção para a capacitação adequada dos enfermeiros na área de saúde do idoso na ESF no cuidar deste segmento populacional, e que possam executar ações de desenvolvimento de condutas preventivas, compreendendo o idoso como ser sexualmente ativo e, assim, como um indivíduo dentro da sua multidimensionalidade.

\section{REFERÊNCIAS}

1. Schimidt TCGS, Silva MJP. Percepção e compreensão de profissionais e graduandos de saúde sobre o idoso e 0 envelhecimento humano. Rev Esc Enferm USP [periódico na Internet]. 2012 Spring [acesso em 2013 fev 12]; 46(3): 612-7. Disponível em: http://www.scielo.br/pdf/ reeusp/v46n3/12.pdf

2. Ciosak SI, Braz E, Costa MFBNA, Nakano NGR, Rodrigues J, Alencar RA, Rocha ACAL. Senescência e senilidade: novo paradigma na atenção básica de saúde. Rev Esc Enferm USP [periódico na Internet]. 2011 [acesso em 12 fev 2013]; 45(2): 1763-8. Disponível em: http://www.scielo.br/pdf/reeusp/v45nspe2/22.pdf

3. Oliveira MGL. Políticas públicas e idoso. Portal do Envelhecimento. [periódico na internet]. 2005 São Paulo [acesso em 2013 fev 02]. Disponível em: http://www.portaldoenvelhecimento.org.br/acervo/pforum/e qvspp1.htm

4. Castro SFF, Barros Júnior FO. Aids e velhices. Rio de Janeiro: AMC Guedes; 2012.

5. Andrade HAS, Silva SK, Santos MIPO. AIDS em idosos: vivências dos doentes. 2010. Aids em idosos: vivências dos doentes. Esc. Anna Nery [online]. 2010; 14(4):712-9.

6. Paula IA, Guibu IA. DST/AIDS e rede básica: uma integração necessária. São Paulo (SP): Secretaria de Estado da Saúde; 2007. p. 137.

7. Minayo MCS. Pesquisa social: teoria, método e criatividade. Rio de Janeiro: Vozes; 2010.

8. Maschio MBM, Baibino AP, Souza PFR, Kalinke LP. Perfil Comportamental de Idosos com Hiv/Aids Atendidos em um Centro de Referência. 2011. Rev Enferm UFPE [periódico na Internet]. 2013 [acesso em 2013 nov 4]; 7(2): 407-13. Disponível em: http://www.revista.ufpe.br/ revistaenfermagem/index.php/revis

9. Bertoncini BZ, Moraes ZS, Kulkamp IC. Comportamento sexual em adultos maiores de 50 anos Infectados pelo 
HIV. Rev DST [periódico na Internet]. 2007[acesso em 2013 nov 12]; 19(2): 75-9. Disponível em: http://www.scielo.br/scielo

10. Sousa JL. Sexualidade na terceira na terceira idade: Uma discussão da aids, envelhecimento e medicamentos Para disfunção erétil. Rev DST [periódico na internet]. 2008 [acesso em 2013 nov 5]; 20(1): 59-64. Disponível em: http://www.scielo.br/scielo

11. Laroque MF, Affeld AB, Cardoso DH, Souza GL, Santana MG, Lange C. Sexualidade do idoso: comportamento para a prevenção de DST/AIDS. Rev Gaúcha Enferm. [periódico na Internet]. 2011 [acesso em 2013 nov 5]; 32(4): 774-80. Disponível em: http://www.scielo.br/scielo

12. Perdigão IS, Oliveira RCC, Zagnoli SBC, Neves, JAC. Susceptibilidade dos idosos ao vírus da imunodeficiência humana: causas, consequências, políticas e intervenções de enfermagem. Rev Enfermagem Rev. [periódico na internet]. 2013 [acesso em 2013 nov 5]; 16(3). Disponível em: $\quad$ https://www.google.com.br/\#q=Perdig\%C3\% A3o+aids+no+idoso

13. Oliveira JCA, Tavares DMS. Atenção ao idoso na estratégia de Saúde da família: atuação do enfermeiro. Rev. Esc. Enferm. USP [periódico na Internet]. 2010 São Paulo [acesso em 2013 fev 12]; 44(3): 774-81. Disponível em: http://www.scielo.br/pdf/reeusp/v44n3/32.pdf

14. Cunha RB, Teixeira SAQ, Silva MCA. Causas das doenças sexualmente transmissíveis na população idosa: atuação do enfermeiro. Rev Bras Enfem [periódico na Internet]. 2009 [acesso em 12 nov 2013]; 62(3):367-73. Disponível em: http://www.scielo.br

15. Veras R. A longevidade da população: desafios e conquistas. Serv Soc Sociedade 2007; [acesso em 2013 nov 4]; 24(75) Disponível em: http://www.seer.ufsj.edu.br/ index.php/recom/article/viewFile/ 269/362

16. Castro SFF, Nascimento BG, Soares SD, Barros Júnior FC, Sousa CMM, Lago, EC. Sexualidade na terceira idade: a percepção do enfermeiro da estratégia saúde da família. Rev Enferm UFPE on line [periódico na internet]. 2013 Recife [acesso em 2013 nov 8]. 7(10): 5907-14.
Disponível em: file://C:/Users/Susane/Downloads/ ARTIGO\%20AIDS\%202.pdf

17. lacub R. Erótica e velhice: perspectivas do ocidente. São Paulo: Vetor; 2007.

18. Santos AFM, Deveza M. A AIDS como condição crônica e o papel do médico de família e de comunidade e da estratégia de saúde da família. Rev Bras Med Fam Comunidade. [periódico na Internet]. 2012 [acesso em 2013 nov 9]; 7(22):10-2. Disponível em: http://www.facenf.uerj.br/v17n2/v17n2a20.pdf .

19. Freitas RTB, Fernandes BKC, Clares JWB, Freitas MC, Nogueira JM. Consequências biopsicossociais da aids na qualidade de vida de pessoas soropositivas para o HIV 2010. Disponível em: http://www.scielo.br/scielo. [acesso em: 2013 out. 25].

20. Oliveira AJCA, Tavares DMS. Atenção ao idoso na estratégia de Saúde da família: atuação do enfermeiro. Rev Esc Enferm USP [periódico na internet]. 2010 [acesso em 2013 fev 12]; 44(3):774-81. Disponível em: http://www.scielo.br/pdf/reeusp/v44n3/32.pdf

21. Lima CA, Tocantins FR. Necessidades de saúde do idoso: perspectivas para a enfermagem. Rev. Bras. Enfem [periódico na Internet]. 2009 [acesso em fev 12]; 62(3): 367-73. Disponível em: http://www.scielo.br.

22. Santos MFA, Assis M. Vulnerabilidade das Idosas ao Hiv/Aids: despertar das políticas públicas e profissionais de saúde no contexto da atenção integral: revisão de literatura. Rev Bras Geriatr Gerontol 2011; 14(1): 147-57.

23. Stumm EMF, Abreu PB, Ubesse LD, Barbosa DA. Estressores e atenuantes de estresse entre idosos em tratamento dialítico Rev Ciência Saúde 2013; 6(1):2-11.

\section{Endereço para correspondência:}

Susane de Fátima Ferreira de Castro

Rua Doutora Maria Carvalho Santos n²033, Apto. 204

Teresina/PI - CEP 64052-465

Telefone: +55 19991883221

E-mail: susaneffcastro@hotmail.com 